\title{
Clinical profiles, medical complications and quality of life of children diagnosed with thalassaemia major in Peradeniya Teaching Hospital
}

\author{
*Kavinda Chandimal Dayasiri ${ }^{1}$, Asanga Kulathilake ${ }^{2}$, Rasnayaka M Mudiyanse ${ }^{2}$
}

Sri Lanka Journal of Child Health, 2018; 47: 112-117

\begin{abstract}
Background: Thalassaemia presents a range of serious clinical and psychological challenges during its clinical course. Only limited data exists regarding health related quality of life of children with beta thalassemia major in Sri Lanka.
\end{abstract}

Objectives: To assess the physical, social, and emotional health of children more than 12 years of age with beta thalassemia major at the Professorial Paediatric Unit, Teaching Hospital Peradeniya, Sri Lanka and to identify the clinical profiles and medical complications among these children.

Method: This case control study included all children $(n=40)$ diagnosed with thalassemia major and who were above 12 years of age at professorial paediatric unit, Teaching Hospital Peradeniya (THP), Sri Lanka. Clinical profiles, medical complications and physical, emotional and social health related quality of life of the participant children were assessed over a period of six months and were compared with age and gender matched control group of children selected from the medical wards of THP who did not have any chronic illnesses.

Results: Forty patients were available for analysis and the mean age was 17 years (range 12-24 years). Twenty $(50 \%)$ were females. Thirty $(75 \%)$ fathers and $28(70 \%)$ mothers had received secondary education. Sixteen (40\%) had delayed puberty, 17 (42.5\%) had short stature and 11 (27.5\%) had hypothyroidism. Restriction of sports, academic failure and restriction of leisure activities had the most impact as individual factors determining physical health in older children.

${ }^{1}$ Lady Ridgeway for Hospital for Children, Colombo, Sri Lanka, ${ }^{2}$ Faculty of Medicine, University of

Peradeniya, Sri Lanka

*Correspondence: mbkcdayasiri@gmail.com

(Received on 11 June 2017: Accepted after revision on 28 July 2017)

The authors declare that there are no conflicts of interest

Personal funding was used for the project.

Open Access Article published under the Creative

Commons Attribution CC-BY CC (i)
The psychological health was adversely affected by altered physical appearance, delayed pubertal features and being labelled with a debilitating illness in both age groups of children with beta thalassemia. The families of these children had faced significant financial and transport difficulties and risk of lack of care to siblings. Most parents believed that services from social support group were required.

Conclusions: Factors underpinning the quality of life of patients with thalassemia above 12 years of age at professorial paediatric unit, Teaching hospital Peradeniya were diverse and included physical, psychological, social and family health related factors. The effect of most factors determining physical health increased with increased age of patients with thalassemia.

DOI: http://dx.doi.org/10.4038/sljch.v47i2.8475

(Key words: Thalassaemia major, medical complications, quality of life, children)

\section{Introduction}

The effects of thalassaemia major on physical health can lead to physical deformity, growth retardation and delayed puberty ${ }^{1}$. The life expectancy of patients with thalassaemia major has significantly increased in recent years, as reported by several groups in different countries $^{2}$. Evaluation of the quality of life (QOL) encompasses a more holistic approach to assess patients' well-being beyond optimum hospital based care and focuses on individual's own views of health ${ }^{3}$. There are several Asian studies published on QOL of thalassaemia patients. Approximately comparable QOL scores were observed in Paediatric Quality of Life Inventory (PEDsQL) assessments in studies from Malaysia $^{4}$, Thailand ${ }^{5}$, Hong Kong ${ }^{6}$ and Jordan ${ }^{7}$. A study involving children of Middle Eastern origin showed that delayed start of iron chelation had a negative impact on the quality of life ${ }^{8}$. South Asian studies on QOL of children with thalassaemia major are few and one such study from India found anxiety and depression related problems to be present in more than $50 \%{ }^{9}$.

A decade ago, expenditure on the management of thalassaemia patients accounted for approximately $5 \%$ 
of the health budget of Sri Lanka ${ }^{10}$. This figure has remained static over the past decade ${ }^{11}$. Limited data exist regarding the Health Related Quality of Life (HRQoL) of children with beta thalassaemia major ${ }^{13}$. Preliminary studies in Sri Lanka have indicated that genetic disorders pose a particularly severe social and psychological impact. There have been a number of cases of broken marriages, family disharmony, depression and stigmatizations caused primarily by the underlying genetic disorder ${ }^{14}$. Up to date there have been no controlled studies in Sri Lanka which evaluated the QOL of children diagnosed with beta thalassaemia major.

\section{Objectives}

- To assess the physical, social, and emotional health of children more than 12 years of age with beta thalassaemia major at the Professorial Paediatric Unit, Teaching Hospital Peradeniya (THP), Sri Lanka.

- To identify the clinical profiles and medical complications among these patients with beta thalassemia major.

\section{Method}

This hospital based case-control study was conducted from April to October 2015, a period of six months, at the Professorial Paediatric Unit, THP, Sri Lanka on all children diagnosed with beta thalassemia major who were above 12 years of age. Only children above 12 years of age were recruited to the study as they faced increased demands with changing expectations in life and were likely to perceive more adverse QOL compared to younger children. Children from the medical wards of THP who presented with acute medical illness, without any history of chronic medical illness, were recruited as controls. Parents of children in the control group were interviewed during visiting hours. All 'cases' were matched for age and gender on an individual patient basis. Each group comprised 40 children adding to a total number of 80 children.

Data were collected from parents of the 80 children recruited to the 'case' and 'control' groups by the principal investigator himself to minimise interviewer bias. Data were collected using a pretested structured questionnaire which comprised questions to identify demographic data, medical complications and the physical, emotional and social health related factors determining QOL and by qualitative evaluation via focused group discussions. The questionnaire was translated into Sinhala and Tamil but was not validated to local languages. The study instruments were pretested by administration of the questionnaire to ten parents of children with beta thalassaemia in the same study setting over a two month period prior to commencement of the study. The investigators proposed and designed a QOL questionnaire themselves and this was administered following careful pretesting, assessment by the psychometrician, and expert review. The semi-structured questionnaire comprised questions that evaluated QOL of children in three main domains, namely (1) Parental opinion on physical related issues in the child, (2) Effect on the psychological health of the child, and (3) Effect on the family. The responses to all questions were rated on a Likert scale ranging from 1 (least severe) to 10 (most severe).

Medical complications were assessed on objective criteria. Medical records were reviewed to identify hypothyroidism, hypoparathyroidism, diabetes, cirrhosis and cardiac failure. Short stature was defined for the study as a height more than two standard deviations below the mean for age and gender. Delay in puberty was identified by lack of secondary sexual characteristics by 13 years in a boy and 14 years in a girl. Hypersplenism was defined for the study as the presence of thrombocytopenia and/or neutropenia in a child with a palpable spleen. All children were on iron chelation therapy and a serum ferritin (performed within one month at the time of recruitment to the study) level of more than 1000 $\mathrm{ng} / \mathrm{ml}$ was defined as iron overload. Recurrent infections were defined for the study as the presence of two or more infections (upper and lower respiratory tract infections, peritonitis, and meningitis) needing hospitalization within a one year period. Arthropathy was identified following the clinical evaluation by the paediatric specialist. Magnetic resonance imaging (MRI) studies for cardiac and liver iron overload could not be performed due to the lack of facilities.

All data were analysed using SPSS version 19.0. Ethical approval for the study was obtained from the Ethical Review Committee, Faculty of Medicine, University of Peradeniya, Sri Lanka. Written consent was obtained from parents of children whose children were less than 18 years old along with assent from those children. Written consent was obtained from both children and parents where children were more than 18 years old.

\section{Results}

Forty patients were available for analysis and the mean age was 17 years (range 12-24 years). Twenty (50\%) were female. Thirty (75\%) fathers and $28(70 \%)$ mothers had received secondary education. Twelve $(30 \%)$ fathers were manual labourers while 35 $(87.5 \%)$ mothers were housewives. Mean monthly income of a family was 13,000 Sri Lankan rupees (LKR) (range 5000 - 55,000 LKR). Thirty two (80\%) 
were nuclear families. Extended family member was available for care of the child in only $6(15 \%)$ of the families. Seven $(17.5 \%)$ of children had a family history of beta thalassemia major.

Children with beta thalassemia major belonged to 34 Medical officer of Health (MOH) administrative divisions. Thirty four $(85 \%)$ children were residing in the Kandy district, 2 each in the Nuwara-Eliya and Matale districts and one each in the Kurunegala and Anuradhapura districts. Twenty nine $(72.5 \%)$ were travelling to the hospital for monthly transfusions by public transport, $6(15 \%)$ children travelled by three wheelers, $6 / 40)$, and $5(12.5 \%)$ by motor bicycles. The caregiver who usually accompanied the child for regular hospitalizations was mother in $24(60 \%)$ children, father in $13(32.5 \%)$ children and extended family member in $3(7.5 \%)$ children.

Mean age at diagnosis of beta thalassemia major was six months (range 4 months $-1 \frac{1}{2}$ years). Seventeen $(42.5 \%)$ had been splenectomised. All were on regular iron chelation therapy and 3-4 weekly blood transfusions. Mean serum ferritin level (reported within one month) was $1900 \mathrm{ng} / \mathrm{ml}$ (range $800 \mathrm{ng} / \mathrm{ml}-$ $8600 \mathrm{ng} / \mathrm{ml}$ ).

Table 1 gives the medical complications of beta thalassemia major. There were no transfusion transmitted infections. One patient died during the study period following chronic liver failure and congestive cardiac failure.
Table 1

Medical complications of beta thalassemia major

\begin{tabular}{|l|c|}
\hline \multicolumn{1}{|c|}{ Complication } & Number (\%) \\
\hline Iron overload & $37(92.5)$ \\
\hline Hypoparathyroidism & $01(02.5)$ \\
\hline Hypothyroidism & $11(27.5)$ \\
\hline Diabetes mellitus & $05(12.5)$ \\
\hline Liver dysfunction & $02(05.0)$ \\
\hline Cardiac failure & $02(05.0)$ \\
\hline Delayed puberty & $16(40.0)$ \\
\hline Short stature & $17(42.5)$ \\
\hline Arthropathy & $01(02.5)$ \\
\hline Recurrent infections & $02(05.0)$ \\
\hline Hypersplenism & $07(17.5)$ \\
\hline
\end{tabular}

Parent reporting of physical health related QOF of children

Of 16 schoolchildren in the study $03(18.7 \%)$ missed school at least 5 days every month due to monthly hospitalizations and thalassemia related morbidities. Of the 40 children 16 (40\%) felt unhappy about abdominal scars due to desferrioxamine chelation therapy. Two (5\%) patients had osteoporotic fractures of which one child remained immobilized during the study period due to stabilization of multiple femur fractures.

Table 2 shows the comparison of the means of each of the items tested on Likert scale (1-10) among the 1218 and $>18$ year age group patients with the control group. The paired student t-test was applied to evaluate significance.

Table 2: Physical health related quality of life parameters

\begin{tabular}{|l|c|c|c|c|c|c|}
\hline \multirow{2}{*}{ Quality of Life Parameter } & \multicolumn{2}{c|}{$\mathbf{1 2 - 1 8}$ years $(\mathbf{n = 1 9})$} & \multicolumn{3}{c|}{$>\mathbf{1 8}$ years $(\mathbf{n = 2 1 )}$} \\
\cline { 2 - 7 } & $\begin{array}{c}\text { Patient } \\
\text { Mean }\end{array}$ & $\begin{array}{c}\text { Control } \\
\text { Mean }\end{array}$ & $\boldsymbol{p}$ & $\begin{array}{c}\text { Patient } \\
\text { Mean }\end{array}$ & $\begin{array}{c}\text { Control } \\
\text { Mean }\end{array}$ & $\boldsymbol{p}$ \\
\hline Pain during routine work & 2.5 & 1.1 & 0.036 & 3.7 & 1.3 & 0.029 \\
\hline Disturbed sleep & 1.8 & 1.1 & 0.5 & 2.0 & 1.2 & 0.03 \\
\hline Restriction of sports & 2.3 & 2.3 & - & 5.2 & 1.2 & 0.0001 \\
\hline Restriction of leisure activities & 3.4 & 1.9 & 0.036 & 3.8 & 1.1 & 0.011 \\
\hline Improper eating habits & 2.8 & 1.2 & 0.003 & 2.8 & 1.7 & 0.029 \\
\hline Peer relationship difficulties & 2.1 & 1.1 & 0.014 & 1.7 & 1.1 & 0.087 \\
\hline Family relationship difficulties & 1.9 & 1.1 & 0.021 & 1.8 & 1.2 & 0.074 \\
\hline Academic activities & 4.0 & 1.2 & 0.0002 & 5.4 & 1.5 & 0.002 \\
\hline
\end{tabular}

Parent reporting of child's psychological health parameters

Parents reported on the same rating scale as to how they understood their children were worrying over four factors, namely (1) increased skin pigmentation, (2) changed physical appearance, (3) delayed appearance of pubertal milestones and (4) feeling of being labelled with a debilitating illness. Means of each of each item in the two groups were calculated and paired student t-test was applied. Table 3 shows comparison of the two age groups with the control group. 
Table 3: Psychological health characteristics of children with beta thalassemia major

\begin{tabular}{|l|c|c|c|c|c|c|}
\hline \multicolumn{1}{|c}{ Quality of Life Parameter } & \multicolumn{2}{|c|}{$\mathbf{1 2 - 1 8}$ years $(\boldsymbol{n}=19)$} & \multicolumn{3}{c|}{$>18$ years $(\boldsymbol{n}=\mathbf{2 1})$} \\
\cline { 2 - 7 } & $\begin{array}{c}\text { Patient } \\
\text { Mean }\end{array}$ & $\begin{array}{c}\text { Control } \\
\text { Mean }\end{array}$ & $\boldsymbol{p}$ & $\begin{array}{c}\text { Patient } \\
\text { Mean }\end{array}$ & $\begin{array}{c}\text { Control } \\
\text { Mean }\end{array}$ & $\boldsymbol{p}$ \\
\hline Worried about increased skin pigmentation & 4.6 & 1.1 & 0.003 & 3.9 & 1.3 & 0.029 \\
\hline Worried about changed facial appearance & 4.8 & 1.2 & 0.002 & 4.9 & 1.1 & 0.003 \\
\hline $\begin{array}{l}\text { Worried about delayed appearance of pubertal } \\
\text { milestones }\end{array}$ & 4.3 & 1.0 & 0.041 & 4.1 & 1.0 & 0.032 \\
\hline Feeling of being labelled with a debilitating illness & 3.4 & 1.0 & 0.036 & 3.7 & 1.0 & 0.0109 \\
\hline
\end{tabular}

Children with beta thalassemia major in both age groups showed that they were having significant psychological stresses related to altered facial appearance and skin hyperpigmentation. Similarly, those children felt that they were having a debilitating illness and their pubertal milestones were delayed compared to the control group and the differences of the two mean scores were significant.

Family health and social related quality of life Twelve (30\%) of the families had severe economic problems (mean score $\geq 7$ ). Twelve $(30 \%)$ of the families strongly believed (mean score $\geq 7$ ) that they need assistance from a social support service. Two
(5\%) parents lost occupation due to child related commitments. Thirteen (32.5\%) had transport difficulties in attending for monthly blood transfusions with mean score $\geq 7$. Four $(10 \%)$ parents believed that that their children's overall health were poor.

Means of each of the items tested on Likert scale (110) among 12-18 and $>18$ year age group patients were compared with the control group. Table 4 shows family health and social related quality of life parameters in the two age groups as compared with the control group.

Table 4: Family health and social related quality of life parameters

\begin{tabular}{|l|c|c|c|c|c|c|}
\hline \multicolumn{1}{|c|}{ Effect } & \multicolumn{2}{c|}{$\mathbf{1 2 - 1 8}$ years $(\boldsymbol{n}=\mathbf{2 1})$} & \multicolumn{3}{c|}{$>\mathbf{1 8}$ years $(\boldsymbol{n}=\mathbf{2 1})$} \\
\hline & $\begin{array}{c}\text { Patient } \\
\text { Mean }\end{array}$ & $\begin{array}{c}\text { Control } \\
\text { Mean }\end{array}$ & $\boldsymbol{p}$ & $\begin{array}{c}\text { Patient } \\
\text { Mean }\end{array}$ & $\begin{array}{c}\text { Control } \\
\text { Mean }\end{array}$ & $\boldsymbol{p}$ \\
\hline Lack of care for other children & 2.0 & 1.0 & 0.0109 & 1.9 & 1.1 & 0.029 \\
\hline Financial difficulties & 6.1 & 3.9 & 0.0885 & 5.4 & 1.2 & 0.004 \\
\hline Need for support from social service & 5.8 & 1.4 & 0.0063 & 6.3 & 1.0 & 0.002 \\
\hline Parents' occupations affected by child's illness & 5.2 & 1.0 & 0.0032 & 4.7 & 1.3 & 0.007 \\
\hline Transport difficulties & 7.1 & 1.8 & 0.0002 & 4.38 & 1.2 & 0.006 \\
\hline
\end{tabular}

Parents of children with beta thalassemia major in both age groups believed that they had financial and transport difficulties, and needed the services from a social support group. The differences of the mean score were significant compared to the control group. The same parents noticed significant possibility of lack of care to their other children while looking after children with beta thalassemia major. The study noted increased effect on all considered domains of family and social health related quality of life among children with thalassaemia compared with the control group.

\section{Discussion}

Thalassaemia major adversely affects physical, psychological and social health related quality of life (HRQOL). A recent cross-sectional study in Sri Lanka reported that lack of family support, female gender and longer clinic admission were determinants of QOL and higher depression scores ${ }^{14}$. The same study observed that peer support was associated with better outcomes. The current study observed that children with thalassaemia had significant relationship difficulties with peers and family compared to children without any chronic illnesses. HRQOL is a multidimensional concept that focuses on the impact of disease and its treatment on the well-being of the patient. There were no previous studies in Sri Lanka that compared HRQOL of children with thalassaemia major to a control group of children without any chronic illnesses. The first controlled study providing evidence on HRQOL of thalassaemia patients was based in Malaysia and it showed lower HRQOL of thalassaemia patients compared with healthy controls ${ }^{4}$. Thalassaemia reduced HRQOL in those children by $10-24 \%$ in that study ${ }^{4}$. A similar study in Iran found $14-23 \%$ reduction of HRQOL in thalassaemia paediatric patients compared with healthy children ${ }^{15}$. The current study did not calculate 
an overall quality of life score. However, the study observed that significantly higher rating scores in physical, psychological and social health determining factors among children with beta thalassaemia and the rates were highest in older children with beta thalassemia in most domains.

A Jordanian study showed that the key domains of quality of life affected in thalassemia children were related to physical well-being and academic underachievement ${ }^{7}$. A study from South Asia ${ }^{16}$ found psychological and physical well-being related more with overall quality of life. Similarly, the current study found that academic underachievement was felt fivefold by children with thalassaemia compared to the controls and all domains of physical well-being were adversely affected among thalassaemia patients. Physical HRQOL was poorer in older children $(>18$ years) with beta thalassaemia compared to $12-18$ year old children.

A study from India ${ }^{17}$ observed that $70 \%$ of caregivers of thalassaemia children had psychiatric problems and $73 \%$ worried about family finances. The caregivers of older patients ( $>18$ years) in the current study felt significantly higher financial difficulties than the caregivers in the control group. A recently published Northern Indian case-control study reported that QOL among children with thalassaemia was significantly worse in emotional and school functioning, and physical and social health ${ }^{18}$. Similar observations were seen in this study. We did not observe any association of gender with QOL scores. It has been similarly observed in certain studies ${ }^{18}$ while other studies have reported female gender as a significant determinant of adverse quality of health ${ }^{14}$.

One limitation of this study is that T2* MRI facility was not available to Teaching hospital Peradeniya to quantify cardiac and liver haemosiderosis. Therefore the investigators had to rely on opinion of radiologists and paediatric cardiologists combined with 2D Echo, laboratory and clinical data to decide on cardiac and liver haemosiderosis.

\section{Conclusions}

Factors underpinning the quality of life of patients with thalassemia above 12 years of age at professorial paediatric unit, Teaching hospital Peradeniya were diverse and included physical, psychological, social and family health related factors. The effect of most factors determining physical health increased with increased age of patients with thalassemia.

\section{References}

1. De Sanctis V, Roos M, Gasser T, Fortini M, Raiola G, Galati MC et al. Impact of longterm iron chelation therapy on growth and endocrine functions in thalassaemia. Journal of Pediatric Endocrinology and Metabolism 2006; 19(4):471-80.

PMid: 16759032

2. Centers for Disease Control and Prevention (CDC). Health-related quality of life. Available from: https://www.cdc.gov/hrqol/

3. Telfer P, Constantinidou G, Andreou P, Christou S, Modell B, Angastiniotis M. Quality of life in thalassaemia. Annals of the New York Academy of Sciences 2005; 1054:273-82.

https://doi.org/10.1196/annals.1345.035

PMid: 16339675

4. Ismail A, Campbell MJ, Ibrahim HM, Jones GL: Health related quality of life in Malaysian children with thalassaemia. Health and Quality of Life Outcomes. 2006; 4: 39.

https://doi.org/10.1186/1477-7525-4-39

PMid: 16813662 PMCid: PMC1538578

5. Thavorncharoensap M, Torcharus K, Nuchprayoon I, Riewpaiboon A, Indaratna K, Ubol BO: Factors affecting health-related quality of life in Thai children with thalassaemia. BMC Blood Disorders. 2010, 10: $1-10$.

PMid: 20180983 PMCid: PMC2836992

6. Cheuk DK, Mok AS, Lee AC, Chiang AK, Ha SY, Lau YL, et al. Quality of life in patients with transfusion-dependent thalassemia after hematopoietic SCT. Bone Marrow Transplant. 2008, 42: 319-27. https://doi.org/10.1038/bmt.2008.165 PMid: 18560410

7. Gharaibeh HF, Gharaibeh MK: Factors influencing health-related quality of life of thalassaemic Jordanian children. Child Care Health and Development 2012; 38: 211-8. https://doi.org/10.1111/j.13652214.2011.012 24.x

PMid: 21426370 
8. Caocci G, Efficace F, Ciotti F, Roncarolo MG, Vacca A, Piras E et al. Health related quality of life in Middle Eastern children with beta-thalassaemia. Blood Disorders. 2012; 12:6.

https://doi.org/10.1186/1471-2326-12-6

PMid: 22726530 PMCid: PMC3496588

9. Shaligram D, Girimaji SC, Chaturvedi SK. Psychological problems and quality of life in children with thalassaemia. Indian Journal of Pediatrics 2007; 74(8):727-30. https://doi.org/10.1007/s12098-007-0127-6 PMid: 17785893

10. de Silva S, Fisher CA, Premawardhena A, et al. Thalassaemia in Sri Lanka: implications for the future health burden of Asian populations. Lancet 2000; 355: 786-91. https://doi.org/10.1016/S01406736(99)0824 $6-\mathrm{X}$

11. Gooneratne LV, Dissanayake R, Jayawardena A, Jayaweera G, Abayadeera A, Samarasinghe $\mathrm{M}$ et al. Allogeneic bone marrow transplant in a child with thalassaemia. Ceylon Medical Journal 2015; 60: $74-5$.

https://doi.org/10.4038/cmj.v60i2.8159

PMid: 26132193

12. Management of haemoglobin disorders. Report of Joint WHO-TIF Meeting, 2007.

13. Premawardhena A, De Silva S, Arambepola $\mathrm{M}$, Olivieri N, Merson L, Muraco J, et al. Thalassaemia in Sri Lanka: a progress report. Human Molecular Genetics 2004; 13(suppl 2): R203-R206 https://doi.org/10.1093/hmg/ddh250

PMid: 15358726
14. Beamish, P. Patel P, Da Silva T, Kaushalya $\mathrm{D}$, Premawardhena A, et al. Examining depression and quality of life in patients with Thalassemia in Sri Lanka. Annals of Global Health 2016; 82(3): 551-2. https://doi.org/10.1016/j.aogh.2016.04.485

15. Baghianimoghadam MH, Sharifirad G, Rahaei Z, Baghianimoghadam B, Heshmati $H$. Health related quality of life in children with thalassaemia assessed on the basis of SF-20 questionnaire in Yaad, Iran: a case control study. Central European Journal of Public Health 2011; 19(3): 165-9.

PMid: 22026294

16. Ammad SA, Mubeen SM, Shah SF, Mansoor S. Parents' opinion of quality of life (QOL) in Pakistani thalassaemic children. Journal of the Pakistan Medical Association 2011; 61(5):470-3.

PMid: 22204182

17. Shaligram D, Girimaji SC, Chaturvedi SK. Quality of life issues in caregivers of youngsters with thalassaemia. Indian Journal of Pediatrics 2007; 74(3):275-8. https://doi.org/10.1007/s12098-007-0043-9

PMid: 17401267

18. Gupta M, Jindal R. Quality of Life in patients with thalassaemia major. International Journal of Science and Research 2016; 5(5): 41- 2. 